Çukurova Üniversitesi Mühendislik Mimarlık Fakültesi Dergisi, 32(1), ss. 31-37, Mart 2017

Çukurova University Journal of the Faculty of Engineering and Architecture, 32(1), pp. 31-37, March 2017

\title{
İnşaat Mühendisleri Özelinde Eş Zamanlı Mühendislik Yaklaşımının İrdelenmesi
}

\author{
Olcay GENÇ ${ }^{* 1}$, Ercan ERDIŞ⿻ ${ }^{1}$, Hilmi COŞKUN ${ }^{1}$

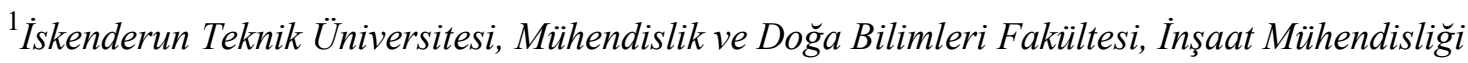 \\ Bölümü, Hatay
}

Geliş tarihi: 03.01.2017 Kabul tarihi:14.03.2017

\section{$\ddot{O} z$}

İnşaat sözleşmelerinde iş sahipleri, mimarlar, mühendisler ve müteahhitler gibi farklı taraflar projenin farklı aşamalarına dahil olurlar. Birçok paydaşın farklı aşamalardaki işe dahil edilmesi genelde bu paydaşların memnuniyetsizliği ile sonuçlanır. Eşzamanlı Mühendislik kavramı tüm paydaşlar için açık bir platform sunarak, artan proje süresi ve yetersiz müşteri memnuniyeti gibi istenmeyen sonuçlar için bir çözüm sunabilir. Bu çalışmanın amacı da, Türkiye'de, kamu ve özel sektörde çalışan inşaat mühendisleri özelinde Eşzamanlı Mühendislik algısının ve bu yaklaşımı etkileyen faktörlerin saptanması ve EM'nin uygulanması sırasında karşılaşılan zorlukların ve uygulamasıyla edinilebilecek faydaların yorumlanması, şeklinde özetlenebilir. Bunun için web tabanlı olarak hazırlanan bir anket, meslek odaları vasıtasıyla Türkiye'nin çeşitli illerinde, kamu ve özel sektörde çalışan inşaat mühendislerine ulaştırılmıştır. Çalışma sonucunda; Türkiye'de kamu ve özel sektörde çalışan inşaat mühendislerinin genel olarak eş zamanlı mühendislik hakkında teorik bilgi sahibi oldukları, fakat çoğunun henüz bunu uygulama olarak tecrübe etmedikleri tespit edilmiştir.

Anahtar kelimeler: Eş zamanlı mühendislik, Müşteri memnuniyeti, Kalite yönetimi

\section{Investigation of Civil Engineers' Concurrent Engineering Approach}

\begin{abstract}
In construction contracts, different parties, such as owners, architectural and engineering consultants, contractors, and users, are involved in different phase of the project. These involvements at different phases usually result dissatisfaction by these parties. Concurrent engineering concept can provide an answer to undesirable outcomes, such as increased project duration and reduced customer satisfaction, by providing an open platform for all involved stakeholders. The purpose of this study is to detect civil engineers', who work for either government or private sector in Turkey' construction industry, a of concurrent engineering (CE), the difficulties encountered during implementation, the benefits of $\mathrm{CE}$ and factors that affect CE. A web-based questionnaire prepared for this purpose and the questionnaire was delivered to civil engineers who work in Turkish public and private sectors through chambers of civil engineers. In conclusion; it is stressed that civil engineers, who work for either government or private sector in Turkey' construction industry, have theoretical knowledge about concurrent engineering but most of them did not experienced the implementation yet.
\end{abstract}

Keywords: Concurrent engineering, Customer satisfaction, Quality management

*Sorumlu (Corresponding author) yazar: Olcay GENÇ, olcay.genc@iste.edu.tr 


\section{GíRiș}

Eşzamanlı mühendislik (EM); kalite, maliyet, zaman ve kullanıcı ihtiyaçları gibi gereklilikleri yerine getirmek için, ürün, süreç ve destek hizmetlerinin eşzamanlı olarak yürütüldüğü sistematik bir yaklaşımıdır [1-3]. Bu yaklaşım, projenin başlangıç aşaması olarak nitelendirilen tasarım aşamasında tüm proje paydaşlarını bir araya getirmeye dönük bir anlayışı temsil etmektedir. Eş zamanlı mühendislik kavramı; bir kuruluşun organizasyon yapısı ve organizasyonda kullanılan farklı araç ve teknikler dikkate alınarak taktiksel açıdan, ürünün tüm aşamalarının paralel olarak kabul edilmesi ile stratejik açıdan ve iş performansını iyileştirmeye yönelik olarak ise nesnel/objektif açıdan değerlendirilmelidir [3]. Bu yönüyle EM; tasarım, inşaat, işletme ve bakım aşamalarındaki kullanıcı ihtiyaçlarını, taktiksel, stratejik ve objektif değerlendirmelerle; kalite, maliyet ve zaman ekseninde daha tasarım aşamasında ve tüm süreç boyunca dengeli bir şekilde geliştirmeye odaklanmış bir yönetim anlayışını temsil etmektedir [4-12].

Eşzamanlı mühendislik yaklaşımı, yazılım ve imalat sektörlerinde daha sık kullanılmaktadır. Bu yaklaşımın uygulanması yönünde, inşaat sektöründe de artan bir ilgi vardır. Bu yaklaşımın geliştirilmesinde rol oynayan ana faktör ise, tüm sektörlerde olduğu gibi, teknolojik gelişmeler doğrultusunda diğer profesyoneller ile işbirliği içinde çalışmalar yapma gerekliliğidir [13].

Eş zamanlı mühendislik kavramını anlamak için, eş zamanlı mühendisliğin iskeleti diğer bir deyişle; hedefler, hedefler arasındaki ilişkiler, stratejiler, araçlar ve tekniklerin belirlenmesi gerekmektedir $[8,10,14]$.

Deasley ve Lettice [15], üretim yapan 20 şirkette, eşzamanlı mühendislik sürecinin uygulanması ve sürdürülebilirliliği ile ilgili yaptıkları çalışmada, süreci; hazırlık, takım çalışması tabanlı entegre ürün geliştirme, çok disiplinli takımların ve organizasyonun yönetimi ve örgütsel yönetim ile süreçlerin geliştirilmesinde kullanılacak geribildirim verilerini saklamak şeklinde gruplandırmışlardır. $\mathrm{Bu}$ şekilde yazarlar bir bakıma, eşzamanlı mühendisliğin çerçevesini çizmişlerdir.

İnşaat sektörü özelinde eşzamanlı mühendisliğin uygulamasında ise sektörün kendisinden kaynaklı özel koşullar nedeniyle bazı zorluklar da yaşanmaktadır. Bunlar aşağıdaki şekilde siralanabilir:

İmalat sektöründe, aynı ürün, aynı tasarım metodolojisini kullanarak birden fazla kez üretilebilir ve seri üretim yapılabilir. Ancak, inşaat sektöründe genel olarak tasarım ve üretim sadece bir kez gerçekleşir [16].

- Tasarım aşamasının inşaat aşamasından ayrı düşünülmesi, müteahhit ve tedarikçilerin tasarım ekibine verimli bir şekilde dahil olmasını imkânsız hale getirir.

- İnşaat işleri çoğunlukla müşterinin mimara verdiği bilgiler çerçevesinde, mimar tarafindan hazırlanan tasarım süreci ile baslar. $\mathrm{Bu}$ tasarım, daha sonra statik hesaplamaları yapması için inşaat mühendisine verilir. Statik hesaplama bitirildikten sonra, proje maliyeti kesin hesapçı tarafindan hesaplanır. Ayni zamanda elektrik, mekanik ve gerekli diğer projeler, ilgili mühendisler tarafından hazırlanır. $\mathrm{Bu}$ işler bittiğinde, proje, işi yapmayı taahhüt eden müteahhitte teslim edilir ve müteahhittin projeyi kabul etmesiyle proje aşaması tamamlanmış olur. İnşaat projelerinin geliştirilmesinde, farklı mesleklere mensup farklı disiplinleri ve uzmanlık alanlarını temsil eden birçok katılımcı vardır. $\mathrm{Bu}$ katılımcıların performansı için kullanılan farklı araç ve farklı metotları verimli bir şekilde entegre etmek kolay bir iş değildir. $\mathrm{Bu}$, görevlerin dikkatli bir şekilde ayrılmasını gerektirir. Projedeki görevlerin birbirine yüksek derecede bağımlılığı sebebiyle, ayırma ve entegrasyon işlemleri başarılı bir şekilde gerçekleştirilmez ise, fonksiyonel bir disiplinin görevini tamamlaması sonrasında disiplinler arası yapay bir duvar oluşumuna neden olabilir. $\mathrm{Bu}$ duvar, her disiplinin birbiri ile etkili bir biçimde iletişim kurmasını engeller ve müşteri ihtiyaçlarının doğru belirlenememesi sonucu hata ve yanlış anlaşılmaların ortaya çıkmasına, maliyet ve süre artışlarına, hatta tasarımda değişikliklere gidilmesine neden olur $[6,14,17]$. 
- EM yaklaşımının uygulanmasında birçok şirket için ana problem, bu yaklaşımın kendisiyle birlikte şirketin yapısında ciddi organizasyonel ve teknolojik değişiklikleri beraberinde getiriyor olmasıdır. Eşzamanlı mühendisliğin uygulanmasına başlanmadan önce önündeki tüm engelleri kaldırmak gerekir. Genellikle şirketlerin kendi organizasyonel yapıları içerisinde, eş zamanlı mühendisliği başarılı bir şekilde uygulayabilmeleri yönünde önlerinde iki büyük engel vardir [16]:

1- Teknik engeller: $\mathrm{Bu}$ engeller genellikle; bir iletişim sisteminin eksikliği, ortak bir veri tabanının olmayışı, CAD/CAM sistemleri, yazılım ve donanım kullanımı hakkındaki bilgi eksiklikleri ve EDM/PDM veri yönetim sistemlerinin kabul edilir şekilde yönetilememesini içerir [16].

2- Organizasyonel engeller: $\mathrm{Bu}$ engeller genel olarak; üst yönetim desteğinin eksikliği, müşteri ve tedarikçilerin projeye katilim eksikliği ve ödüllendirici sistemi desteklemeyen organizasyon yapısı olarak sıralanabilir $[14,18]$.

EM'nin faydaları ise özetle aşağıdaki şekilde siralanabilir [19,20]:

- Müşteri beklentilerini karşılayan yüksek kaliteli düşük maliyetli ürünler.

- Ürün geliştirme surecinde kısalma

- Ürün çeşitliliğinde, satışta ve karda artış

- Düşük ana ekipman maliyeti

- Yeniden tasarım ihtimalinin düşüklüğü

- Daha az satıcidan daha az malzeme

$\mathrm{Bu}$ çalışmanın amacı da, inşaat mühendisleri özelinde EM yaklaşımının algılanma ve uygulanma düzeyini tespit etmektir. Bu doğrultuda kamu ve özel sektörde çalışan inşaat mühendislerinin EM'liği algılama düzeyini ölçmek, EM'yi etkileyen faktörleri saptamak, yöntemin uygulanması sırasında karşılaşılan zorlukları ve uygulamasıyla edinilebilecek faydaları belirlemek için bir anket yapılmıştır.

\section{MATERYAL VE METOT}

$\mathrm{Bu}$ çalışma, web tabanlı bir anketin analizine yöneliktir. Anketin ilk kısmında; eş zamanlı mühendislik algısı, eş zamanlı mühendisliğin uygulanması sırasında karşılaşılan zorluklar, eşzamanlı mühendislik (EM) uygulamasıyla edinilebilecek faydalar ve EM'yi etkileyen faktörler sorgulanırken, ikinci kısım demografik sorulardan oluşmaktadır. Hazırlanan anket linki, meslek odaları vasıtasıyla Türkiye'nin çeşitli ilerinde kamu ve özel sektörde çalışan inşaat mühendislerine ulaştırılmıştır. Link, bir kişinin anketi birden fazla kez yanıtlamasını engellemek amacıyla her alıcı için yalnızca bir kez çalışacak şekilde programlanmıştır. Araştırmanın evreni Türkiye genelinde kamu ve özel sektörde çalışan inşaat mühendisleri olup, örnek uzayı ise 221 adet inşaat mühendisidir. Anket soruları derecelendirme ve değerlendirme (5'li Likert) ölçekleri kullanılarak hazırlanmıştır. Derecelendirme soruları analiz edilirken, ilk sıraya gelen seçeneğe en yüksek puan (örneğin 6 seçenek varsa 6 puan), son sıraya gelen seçeneğe ise en düşük puan (1 puan) olacak şekilde seçenekler arasında puanlama yapılıp ağırlıklı ortalamalar hesaplanmış ve değerlendirmeler bu ortalamaya göre yapılmıştır. Değerlendirme (5'li Likert) soruları analiz edilirken ortalamalar ve standart sapma değerleri baz alınmış ve Çizelge 1'deki puan aralıkları ve değerlendirme kriterleri kullanılmıştır.

Çizelge 1. Likert ölçeği sonuçlarını değerlendirme kriterleri

\begin{tabular}{|c|c|c|c|}
\hline $\begin{array}{c}\text { Likert } \\
\text { Ölçeği }\end{array}$ & Anket & $\begin{array}{c}\text { Puan } \\
\text { Aralıkları }\end{array}$ & $\begin{array}{c}\text { Değerlendirme } \\
\text { Kriterleri }\end{array}$ \\
\hline 1 & $\begin{array}{c}\text { Çok } \\
\text { önemli }\end{array}$ & $4,20-5,00$ & $\begin{array}{c}\text { Çok yüksek } \\
\text { düzeyde }\end{array}$ \\
\hline 2 & Önemli & $3,40-4,19$ & $\begin{array}{c}\text { Yüksek } \\
\text { düzeyde }\end{array}$ \\
\hline 3 & $\begin{array}{c}\text { Orta } \\
\text { derecede } \\
\text { önemli }\end{array}$ & $2,60-3,39$ & Orta düzeyde \\
\hline 4 & $\begin{array}{c}\text { Az } \\
\text { onemli }\end{array}$ & $1,80-2,59$ & Az düzeyde \\
\hline 5 & $\begin{array}{c}\text { Çok az } \\
\text { önemli }\end{array}$ & $1,00-1,79$ & Çok az düzeyde \\
\hline
\end{tabular}




\section{ARAŞTIRMA BULGULARININ DEĞERLENDİRILMESI}

Çalışmanın bulgular kısmı; ülkemiz kamu ve özel sektöründe çalışan inşaat mühendislerinin eş zamanlı mühendislik algısını anlamak, eş zamanlı mühendisliğin uygulanması sırasında karşılaşılan zorlukları, eşzamanlı mühendislik (EM) uygulamasıyla edinilebilecek faydaları ve EM'yi etkileyen faktörlerin saptanması ve yorumlanması üzerine kurgulanmıştır.

Çizelge 2. İnşaat mühendislerinin EM algısı

\begin{tabular}{|l|c|c|}
\hline $\begin{array}{l}\text { “Eşzamanlı Mühendislik" } \\
\text { (EM) kavramı hakkında } \\
\text { bilginiz var mı? }\end{array}$ & f & $\%$ \\
\hline $\begin{array}{l}\text { Bu konuda henüz hiçbir bilgim } \\
\text { yok }\end{array}$ & 76 & 34,4 \\
\hline $\begin{array}{l}\text { İlgi duyuyorum ve bilgi } \\
\text { edinmeye çalışıorum }\end{array}$ & 55 & 24,9 \\
\hline $\begin{array}{l}\text { Biliyorum; ancak, henüz } \\
\text { uygulamasında bulunmadım }\end{array}$ & 48 & 21,7 \\
\hline $\begin{array}{l}\text { Biliyorum ve } \\
\text { uyguluyorum/uyguladım }\end{array}$ & 42 & 19,0 \\
\hline
\end{tabular}

Çizelge 2 incelendiğinde; katılımcıların \%34,4'ünün eş zamanlı mühendislik hakkında bilgisi olmadığ1 görülürken, \%24,9'unun ilgi duyduğu ve bilgi edinmeye çalıştığ $1, \% 21,7$ 'sinin bildiği ancak henüz tecrübe etmediği, \%19,0'unun ise bildiği ve uyguladığı görülmektedir.

Çizelge 3, 5'li Likert ölçeğine göre değerlendirilmiş olup, bu değerlendirmeye göre ankete katılan inşaat mühendisleri, EM' in uygulanması sırasında karşılaşılan zorlukları; eşzamanlı mühendislik kavramının yeterince bilinmemesi, ekip çalışmasının eksikliği, departmanlar arası iletişim ve bilgi paylaşımındaki eksiklikler, projelerde tasarım ve imalat aşamasının ayrılması sonucu uygulamada yer alacak meslek gruplarının tasarım ekibine katılımındaki eksiklik, işverenin tutum ve davranışı (üretim çizgisinde ve şartnamede yaptığ1 değişiklikler, zamanında ödeme yapmayışı vb.), üst yönetimin desteğinin eksikliği, çalışanların yetersizlikleri (yetenekleri, bilgisi, kişiliği, dürüstlüğü, performansı vb.), önemli projelerle ilgili kararlar ve bu kararların alınmasını sağlayan faktörlerin yer aldığı ortak bir veri tabanının olmaması, proje ekiplerinde yapılan ani değişiklikler, gerek tasarım, gerekse yapım aşamasında projede görev alan kişilerin birbirlerine karşı güvensizliği, korkusu ve gördükleri hataları söylememe alışkanlığı, uygulamada çok disiplinli ve geçici organizasyonel yapının varlığı seçeneklerini önemli derecede değerlendirirlerken, diğer seçenekleri orta derecede önemli olarak değerlendirmişlerdir.

Önem derecesinde, eşzamanlı mühendislik kavramının yeterince bilinmemesi 3,92 ağırlıklı ortalama ile ilk sirada değerlendirilirken, projede yer alan meslek gruplarının farklı inançları, değerleri, davranışları, dilleri, alışkanlıkları, yönetme kuralları, beklentileri, norm ve uygulamaları (kültürel problemler) 2,85 ağırlıklı ortalama ile son sirada yer almaktadır. Bu durum yöntemin uygulanması ve başarısında; eşzamanlı mühendislik kavramın yeterince bilinmemesinin önemli olduğuna, organizasyonel kültürün ise önemli olmadığına işaret etmektedir.

Çizelge 4 ağırlıklı ortalamalar göz önüne alınarak incelendiğinde; ankete katılan inşaat mühendisleri, eşzamanlı mühendislik uygulamasıyla edinilebilecek faydaları sıralarken, ilk sıraya daha

kaliteli üretimi koymuşlardır. İkinci ve üçüncü sırada proje maliyetlerinde ve süresinde azalma yer alırken, son sirada rekabet edilebilirlik kapasitesinin artırılması yer almaktadır. 
Çizelge 3. Eşzamanlı mühendisliğin uygulanması sırasında karşılaşılan zorluklar

\begin{tabular}{|c|c|c|c|c|c|c|c|c|c|c|c|}
\hline \multirow{2}{*}{$\begin{array}{l}\text { EM'nin uygulanması sırasında karşılaşılan } \\
\text { zorlukları önem derecesine göre sıralayınız. (1 } \\
\text { en çok önemli, } 5 \text { en az önemli) }\end{array}$} & \multicolumn{2}{|c|}{1} & \multicolumn{2}{|c|}{2} & \multicolumn{2}{|c|}{3} & \multicolumn{2}{|c|}{4} & \multicolumn{2}{|c|}{5} & \multirow{2}{*}{$\begin{array}{l}\text { Ăgr. } \\
\text { Ort. } \\
-\end{array}$} \\
\hline & $\mathbf{f}$ & $\%$ & $\mathbf{f}$ & $\%$ & $\mathbf{f}$ & $\%$ & $\mathbf{f}$ & $\%$ & $\mathbf{f}$ & $\%$ & \\
\hline $\begin{array}{l}\text { Eşzamanlı mühendislik kavramının yeterince } \\
\text { bilinmemesi }\end{array}$ & 117 & 52,9 & 36 & 16,3 & 24 & 10,9 & 21 & 9,5 & 23 & 10,4 & 3,92 \\
\hline Ekip çalışmasının eksikliği & 97 & 43,9 & 57 & 25,8 & 26 & 11,8 & 18 & 8,1 & 23 & 10,4 & 3,85 \\
\hline $\begin{array}{l}\text { Departmanlar arası iletişim ve bilgi paylaşımındaki } \\
\text { eksiklikler }\end{array}$ & 78 & 35,3 & 70 & 31,7 & 30 & 13,6 & 25 & 11,3 & 18 & 8,1 & 3,75 \\
\hline $\begin{array}{l}\text { Projelerde tasarım ve imalat aşamasının ayrılması } \\
\text { sonucu, uygulamada yer alacak meslek gruplarının } \\
\text { tasarım ekibine katılımındaki eksiklik }\end{array}$ & 71 & 32,1 & 71 & 32,1 & 37 & 16,7 & 21 & 9,5 & 21 & 9,5 & 3,68 \\
\hline $\begin{array}{l}\text { İşverenin tutum ve davranışı (Üretim çizgisinde ve } \\
\text { şartnamede yaptığı değişiklikler, zamanında ödeme } \\
\text { yapmayışı vb.) }\end{array}$ & 85 & 38,5 & 49 & 22,2 & 40 & 18,1 & 20 & 9,0 & 27 & 12,2 & 3,66 \\
\hline Üst yönetimin desteğinin eksikliği & 65 & 29,4 & 77 & 34,8 & 39 & 17,6 & 15 & 6,8 & 25 & 11,3 & 3,64 \\
\hline $\begin{array}{l}\text { Çalışanların yetersizlikleri (yetenekleri, bilgisi, } \\
\text { kişiliği, dürüstlüğü, performansı vb.) }\end{array}$ & 70 & 31,7 & 58 & 26,2 & 48 & 21,7 & 30 & 13,6 & 15 & 6,8 & 3,62 \\
\hline $\begin{array}{l}\text { Önemli projelerle ilgili kararlar ve bu kararların } \\
\text { alınmasını sağlayan faktörlerin yer aldığı ortak bir } \\
\text { veri tabanının olmaması }\end{array}$ & 67 & 30,3 & 57 & 25,8 & 58 & 26,2 & 25 & 11,3 & 14 & 6,3 & 3,62 \\
\hline Proje ekiplerinde yapılan ani değişiklikler & 60 & 27,1 & 60 & 27,1 & 49 & 22,2 & 37 & 16,7 & 15 & 6,8 & 3,51 \\
\hline $\begin{array}{l}\text { Gerek tasarım, gerekse yapım aşamasında projede } \\
\text { görev alan kişilerin birbirlerine karşı güvensizliği, } \\
\text { korkusu ve gördükleri hataları söylememe } \\
\text { alışkanlığı }\end{array}$ & 54 & 24,4 & 67 & 30,3 & 55 & 24,9 & 26 & 11,8 & 19 & 8,6 & 3,50 \\
\hline $\begin{array}{l}\text { Uygulamada çok disiplinli ve geçici organizasyonel } \\
\text { yapının varlığ }\end{array}$ & 58 & 26,2 & 57 & 25,8 & 52 & 23,5 & 36 & 16,3 & 18 & 8,1 & 3,46 \\
\hline $\begin{array}{l}\text { Tasarım, imalat ve her türlü bilgi } \\
\text { paylaşımında bilgisayar teknolojisinin yetersiz } \\
\text { kullanımı }\end{array}$ & 48 & 21,7 & 63 & 28,5 & 53 & 24,0 & 33 & 14,9 & 24 & 10,9 & 3,35 \\
\hline Tasarım sürecine müşteri katılımının eksikliği & 51 & 23,1 & 58 & 26,2 & 48 & 21,7 & 40 & 18,1 & 24 & 10,9 & 3,33 \\
\hline $\begin{array}{l}\text { Yapılan işin ardışık ve birbirine bağımlı } \\
\text { görevlerden oluşması }\end{array}$ & 50 & 22,6 & 49 & 22,2 & 66 & 29,9 & 30 & 13,6 & 26 & 11,8 & 3,30 \\
\hline $\begin{array}{l}\text { İşin yapımını etkileyen iç ve dış çevresel faktörlerin } \\
\text { çokluğu ve kompleksliği }\end{array}$ & 39 & 17,6 & 53 & 24,0 & 72 & 32,6 & 40 & 18,1 & 17 & 7,7 & 3,26 \\
\hline $\begin{array}{l}\text { Kuruluşun üretim şekli-Seri üretim veya bir defaya } \\
\text { mahsus üretim vb. }\end{array}$ & 41 & 18,6 & 38 & 17,2 & 81 & 36,7 & 38 & 17,2 & 23 & 10,4 & 3,16 \\
\hline $\begin{array}{l}\text { Tasarım aşamasında kullanılan araç ve gereçlerin } \\
\text { yetersizliği }\end{array}$ & 37 & 16,7 & 52 & 23,5 & 61 & 27,6 & 39 & 17,6 & 32 & 14,5 & 3,10 \\
\hline $\begin{array}{l}\text { Projede yer alan meslek gruplarının farklı inançları, } \\
\text { değerleri, davranışları, dilleri, alışkanlıkları, } \\
\text { yönetme kuralları, beklentileri, norm ve } \\
\text { uygulamaları (Kültürel problemler) }\end{array}$ & 35 & 15,8 & 40 & 18,1 & 53 & 24,0 & 42 & 19,0 & 51 & 23,1 & 2,85 \\
\hline
\end{tabular}

Çizelge 4. Eşzamanlı mühendisliğin faydaları

\begin{tabular}{|c|c|c|c|c|c|c|c|c|c|c|c|c|c|}
\hline \multirow{2}{*}{$\begin{array}{l}\text { Eşzamanlı Mühendislik (EM) } \\
\text { uygulamasıyla edinilebilecek } \\
\text { faydaları en olası fayda } 1 \\
\text { olmak üzere 1' den 6' ya } \\
\text { kadar sıralayınız }\end{array}$} & \multicolumn{2}{|c|}{$\mathbf{1}$} & \multicolumn{2}{|c|}{2} & \multicolumn{2}{|c|}{3} & \multicolumn{2}{|c|}{4} & \multicolumn{2}{|c|}{5} & \multicolumn{2}{|c|}{6} & \multirow{2}{*}{$\begin{array}{r}\text { Ăgr. } \\
\text { Ort. } \\
-\end{array}$} \\
\hline & $\mathbf{f}$ & $\%$ & f & $\%$ & $\mathbf{f}$ & $\%$ & $\mathbf{f}$ & $\%$ & $\mathbf{f}$ & $\%$ & $\mathbf{f}$ & $\%$ & \\
\hline Daha Kaliteli Üretim & 54 & 24,4 & 38 & 17,2 & 56 & 25,3 & 36 & 16,3 & 17 & 7,7 & 20 & 9,0 & 4,07 \\
\hline Proje Maliyetlerinde Azalma & 60 & 27,1 & 42 & 19,0 & 38 & 17,2 & 31 & 14,0 & 24 & 10,9 & 26 & 11,8 & 4,02 \\
\hline Proje Süresinde Azalma & 31 & 14,0 & 63 & 28,5 & 43 & 19,5 & 40 & 18,1 & 30 & 13,6 & 14 & 6,3 & 3,92 \\
\hline $\begin{array}{l}\text { Şirket İçi Etkin Bilgi Yönetimi } \\
\text { (Çalışanlar arası doğru ve hızlı } \\
\text { bilgi akışı) }\end{array}$ & 25 & 11,3 & 33 & 14,9 & 28 & 12,7 & 29 & 13,1 & 64 & 29,0 & 42 & 19,0 & 3,10 \\
\hline Müşteri Memnuniyeti & 37 & 16,7 & 25 & 11,3 & 23 & 10,4 & 25 & 11,3 & 36 & 16,3 & 75 & 33,9 & 2,99 \\
\hline $\begin{array}{l}\text { Rekabet Edilebilirlik } \\
\text { Kapasitesinin Artmas1 }\end{array}$ & 14 & 6,3 & 20 & 9,0 & 33 & 14,9 & 60 & 27,1 & 50 & 22,6 & 44 & 19,9 & 2,90 \\
\hline
\end{tabular}


Çizelge 5. Eşzamanlı mühendisliği etkileyen faktörler

\begin{tabular}{|c|c|c|c|c|c|c|c|c|c|c|c|c|c|c|c|}
\hline \multirow{2}{*}{$\begin{array}{l}\text { EM'yi etkileyen } \\
\text { faktörleri en olası } \\
\text { faktör } 1 \text { olmak } \\
\text { üzere 1' den 7'ye } \\
\text { kadar sıralayınız }\end{array}$} & \multicolumn{2}{|c|}{1} & \multicolumn{2}{|c|}{2} & \multicolumn{2}{|c|}{3} & \multicolumn{2}{|c|}{4} & \multicolumn{2}{|c|}{5} & \multicolumn{2}{|c|}{6} & \multicolumn{2}{|r|}{$A$} & Ağr. Ort. \\
\hline & $\mathbf{f}$ & $\%$ & f & $\%$ & $\mathbf{f}$ & $\%$ & $\mathbf{f}$ & $\%$ & $\mathbf{f}$ & $\%$ & f & $\%$ & $\mathbf{f}$ & $\%$ & - \\
\hline Ekip çalışması & 63 & 28,5 & 39 & 17,6 & 41 & 18,6 & 25 & 11,3 & 18 & 8,1 & 20 & 9,0 & 15 & 6,8 & 4,93 \\
\hline Zaman & 32 & 14,5 & 40 & 18,1 & 34 & 15,4 & 26 & 11,8 & 25 & 11,3 & 27 & 12,2 & 37 & 16,7 & 4,09 \\
\hline Teknoloji & 35 & 15,8 & 19 & 8,6 & 33 & 14,9 & 41 & 18,6 & 39 & 17,6 & 30 & 13,6 & 24 & 10,9 & 4,02 \\
\hline $\begin{array}{l}\text { Görev tariflerini } \\
\text { belirleme }\end{array}$ & 33 & 14,9 & 39 & 17,6 & 18 & 8,1 & 25 & 11,3 & 33 & 14,9 & 40 & 18,1 & 33 & 14,9 & 3,92 \\
\hline $\begin{array}{l}\text { Çalışanların eğitim } \\
\text { sonucu kazandıkları } \\
\text { yetenekler }\end{array}$ & 30 & 13,6 & 34 & 15,4 & 28 & 12,7 & 29 & 13,1 & 30 & 13,6 & 25 & 11,3 & 45 & 20,4 & 3,87 \\
\hline Kullanılan teknikler & 17 & 7,7 & 26 & 11,8 & 41 & 18,6 & 40 & 18,1 & 35 & 15,8 & 42 & 19,0 & 20 & 9,0 & 3,84 \\
\hline Kullanılan araçlar & 11 & 5,0 & 24 & 10,9 & 26 & 11,8 & 35 & 15,8 & 41 & 18,6 & 37 & 16,7 & 47 & 21,3 & 3,33 \\
\hline
\end{tabular}

Çizelge 5 ağırlıklı ortalamalar göz önüne alınarak incelendiğinde; ankete katılan inşaat mühendislerinin, eşzamanlı mühendisliği etkileyen faktörleri sıralarken ilk sıraya ekip çalışmasını koymuşlardır. Bunu sırasıyla, zaman, teknoloji, görev tariflerini belirleme, çalışanların eğitim sonucu kazandıkları yetenekler, kullanılan teknikler ve kullanılan araçlar izlemektedir.

\section{SONUÇLAR ve ÖNERILER}

Çalışma sonucunda, ülkemizde kamu ve özel sektörde çalışan inşaat mühendislerinin; genel olarak eş zamanlı mühendislik hakkında bilgi sahibi oldukları, fakat çoğunun henüz bunu tecrübe etmediği anlaşılmıştır. Yöntemin uygulanması ve başarısında ise; eşzamanlı mühendislik kavramının sektör genelinde yeterince bilinmemesinin, ekip çalışmasının teşvik edilmemesinin, uygulamada yer alan farklı meslek gruplarının tasarım sırasında görüşlerinin alınmamasının, departmanlar arasında ve uygulama aşamasında yer alan birçok geçici organizasyonlar arasında iletişim ve bilgi paylaşımındaki eksikliklerin, işverenin tutum ve davranışının, üst yönetimin desteğinin eksikliğinin, çalışanların yetersizliklerinin, ortak bir veri tabanının olmamasının, proje ekiplerinde yapılan ani değişikliklerin, gerek tasarım, gerekse yapım aşamasında projede görev alan kişilerin birbirlerine karşı güvensizliği, korkusu ve gördükleri hataları söylememe alışkanlığının etkili olduğu anlaşılmıştır. Yine çalışmada, firma genelinde başarılı eşzamanlı mühendislik uygulamaları ile kaliteli üretim gerçekleştirme, proje maliyetlerinde ve süresinde azalmanın mümkün olabileceği sonucuna ulaşılmıştır. $\mathrm{Bu}$ yöntemin ülkemiz inşaat sektöründe de başarılı uygulamalarını görmek, kamu ve özel sektör işbirliği ile mümkün olabilecektir. Bu doğrultuda, özellikle kamu ve özel sektör projelerinde, bu konuda uzmanlaşmış mühendis ve mimarların istihdam edilmesi ve yöntemin proje bazındaki uygulamalarının takip edilerek, başarılı ve başarısız uygulamaların tespit edilmesi, sonrasında ise bunun nedenleri ve çözüm önerilerinin saptanması gerekmektedir.

\section{KAYNAKLAR}

1. De la Garza, J. M., Alcantara, P., Jr., Kapoor, M., Ramesh, P. S., 1994. Value of Concurrent Engineering for $\mathrm{A} / \mathrm{E} / \mathrm{C}$ Industry, Journal of Management in Engineering, 10(3), 46-55.

2. Şekerci, B., 2008. Eşzamanlı Mühendislik Kavramının Türk İnşaat Sektöründe Uygulanabilirlik Düzeyinin İrdelenmesi, Çukurova Üniversitesi Fen Bilimleri Enstitüsü Yüksek Lisans Tezi, 142 p.

3. Shouke, C., Zhuobin, W., Jie, L., 2010. Comprehensive Evaluation for Construction Performance in Concurrent Engineering Environment, International Journal of Project Management, 28(7), 708-718. 
4. Winner, R. I., 1988. The Role of Current Engineering in Weapons System Acquisition, Institute for Defence Analyses, Report R-388.

5. Cleetus, K. J., 1992. Definition of Concurrent Engineering, CERC (Concurrent Engineering Research Center), Technical Report Series, Research Notes, CERC-TR-92003.

6. Anumba, C. J., Evbuomwan, N. F. O., 1997. Concurrent Engineering in Design-Build Projects, Construction Management and Economics, 15(3), 271-281.

7. Anumba, C. J., Baldwin, A. N., Bouchlaghem, D., Parasad, B., Cutting-Decelle, A. F., Dufau, J., Mommessin, M., 2000. Integrating Concurrent Engineering Concepts in a Steelwork Construction Project, Concurrent Engineering: Research and Applications, 8(3), 199-212.

8. Brookes, N. J., Backhouse, C. J., 1998. Understanding CE Implementation: A Case-Study Approach, 36(11), 3035-3054.

9. Love, P., Gunasekaran, A., Li, H., 1998. Concurrent Engineering: A Strategy for Procuring Construction Projects, International Journal of Project Management, 16(6), 375-383.

10. Kamara, J. M., Anumba, C. J., Evbuomwan, N. F. O., 2000. Establishing and Processing Client Requirements-A Key Aspect Concurrent Engineering in Construction, Engineering, Construction and Architectural Management, 7(1), 15-28.

11. Khalfan, M.M.A., Anumba, C.J., Carillo, P.M., 2001. Development of a Readiness Assessment Model for Concurrent Engineering in Construction, Benchmarking: An International Journal, 8(3), 223-239.

12. Khalfan, M. M. A., Anumba, C. J., Siemieniuch, C. E., Sinclair, M.A., 2001. Readiness Assessment of the Construction Supply Chain for Concurrent Engineering, European Journal of Purchasing \& Supply Management, 7(2), 141-153.

13. Erdiş, E., Coşkun, H., Genç, O., 2015. Architects' View of Concurrent Engineering in Construction Projects, International Journal of Thales Engineering Sciences, 1(2), 1-15.

14. Anumba C. J., Baugh C., Khalfan, M. M. A., 2002. Organisational Structures to Support
Concurrent Engineering in Construction, Industrial Management and Data Systems, 102(5-6), 260-270.

15. Deasley P., Lettice F., 1997. A Concurrent Engineering Approach to Construction: Learning from Cases in Manufacturing Industry, Concurrent Engineering in Construction, The Institution of Structural Engineers, London, 296-305.

16. Kamara J. M., Anumba C. J., Evbuomwan N. F. O., 1997. Considerations for the Effective Implementation of Concurrent Engineering in Construction, The Institution of Structural Engineers, London, 33-44.

17. Evbuomwan N. F. O., Anumba C. J., 1998. An Integrated Framework for Concurrent Life-Cycle Design and Construction, Advances in Engineering Software, 29(7-9), 587-597.

18. Parsaei H.R., Sullivan W.G., 1993. Handbook of Concurrent Engineering, Chapman and Hall, London.

19. İstanbul Teknik Üniversitesi, İnşaat Fakültesi, İnşaat Mühendisliği Bölümü web sayfas1, http://web.itu.edu.tr/ livatyali/dersler/mak568e /mak568e_L4_CE.pdf [Erişim tarihi: 22 Nisan 2016].

20. Coşkun, H., Erdiş, E., Genç, O. 2016. Improving the Performance of Construction Projects by Employing Concurrent Engineering. Çukurova Universitesi Mühendislik Mimarlık Fakültesi Dergisi, 31(2), 7-58. 
